\title{
Proviral Loads and Clonal Expansion of HTLV-1-Infected Cells following Vertical Transmission: A 10-Year Follow-Up of Children in Jamaica
}

\author{
Kazumi Umeki ${ }^{a}$ Michie Hisada $^{b}$ Elizabeth M. Maloney ${ }^{c}$ Barrie Hanchard ${ }^{d}$ \\ Akihiko Okayama ${ }^{a}$ \\ a Department of Rheumatology, Infectious Diseases and Laboratory Medicine, University of Miyazaki, Miyazaki, Japan; \\ ${ }^{b}$ Division of Cancer Epidemiology and Genetics, NCl, Rockville, Ind., and ${ }^{C}$ Centers for Disease Control and Prevention, \\ Atlanta, Ga., USA; ${ }^{\mathrm{d}}$ Department of Pathology, University of the West Indies, Mona, Jamaica
}

\section{Key Words}

HTLV-1 infection • Clonal expansion, infected cells •

Transmission, vertical

\begin{abstract}
Objective: Few studies have specifically examined proviral load (PVL) and clonal evolution of human T-lymphotropic virus type 1 (HTLV-1)-infected cells in vertically infected children. Methods: Sequential samples (from ages 1 to 16 years) from 3 HTLV-1-infected children (cases A, B and C) in the Jamaica Mother Infant Cohort Study were analyzed for their PVL and clonal expansion of HTLV-1-infected cells in peripheral blood mononuclear cells (PBMCs) by inverse-long PCR. Results: The baseline PVL (per 100,000 PBMCs) of case A was 260 (at 1 year of age) and of case B it was 1,867 (at 3 years of age), and they remained constant for more than 10 years. Stochastic patterns of clonal expansion of HTLV-1-infected cells were predominately detected. In contrast, case $C$, who had lymphadenopathy, seborrheic dermatitis and hyperreflexia, showed an increase in PVL from 2,819 at 1.9 years to 13,358 at 13 years of age, and expansion of 2 dominant clones. Conclusion: The clonal expansion of HTLV-1-infected cells is induced in early childhood after infection acquired
\end{abstract}

from their mothers. Youths with high PVL and any signs and symptoms associated with HTLV-1 infection should be closely monitored.

Copyright $\odot 2009$ S. Karger AG, Basel

\section{Introduction}

Human T-lymphotropic virus type 1 (HTLV-1) is a causative agent of adult T-cell leukemia/lymphoma (ATL) and a progressive neurological disease known as HTLV1-associated myelopathy/tropical spastic paraparesis [13]. The majority of HTLV-1 carriers are asymptomatic, and only a fraction of carriers develop ATL after a long latent period $[4,5]$. High proviral load (PVL) has been considered to be important for developing ATL. It has been shown that PVL vary substantially among adult HTLV-1 carriers, whereas within the same individual, PVL appears to remain relatively stable for many years [6-8]. Most mothers of patients with ATL are themselves HTLV-1 carriers $[9,10]$. Therefore, ATL is believed to develop in HTLV-1 carriers who acquired infection perinatally. A study in perinatally infected children demonstrated variation of initial PVL [11]. In children with 
Table 1. Clinical signs and symptoms observed in case $C$

\begin{aligned} & \hline $\begin{array}{l}\text { Age } \\ \text { (years) }\end{array}$ Clinical signs and symptoms \\ & \hline 0.5 Inguinal lymphadenopathy \\ & 2.0 Abnormal lymphocyte finding $(2 \%) \\ & 5.5$ Seborrheic dermatitis \\ & 6.0 Eczema, axillary lymphadenopathy \\ & 6.5 Inguinal lymphadenopathy \\ & 8.5 Axillary lymphadenopathy \\ & 9.0 Persistent hyperreflexia, posterior cervical lymph- \\ & adenopathy \\ & 9.5 Inguinal lymphadenopathy \\ & 10.0 Inguinal lymphadenopathy (diameter $2 \mathrm{~cm}) \\ & 16.0$ No particular symptom \\ & \hline\end{aligned}

HTLV-1 infection, the association of infective dermatitis and seborrheic dermatitis is documented $[12,13]$. The HTLV-1 carrier children with these skin manifestations have been reported to have high PVL in their peripheral blood mononuclear cells (PBMCs) [11, 14]. Moreover, epidemiological data have suggested that infective dermatitis might foreshadow ATL and HTLV-1-associated myelopathy/tropical spastic paraparesis $[15,16]$.

It is thought that HTLV-1 Tax protein drives proliferation of the infected cells, leading to the clonal expansion of certain HTLV-1-infected cells, which subsequently results in onset of ATL $[6,17-19]$. It is uncertain whether and when such clonal expansion occurs in relation to PVL among children who acquire infection perinatally. To investigate the co-evolution of HTLV-1-infected clones and PVL during the early years of HTLV-1 infection in children, we analyzed sequential samples drawn from 3 children carrying HTLV-1 who were longitudinally followed for over 10 years.

\section{Materials and Methods}

\section{Cases}

The sequential samples of PBMCs obtained from 3 children carrying HTLV-1 (cases A, B and C) in the Jamaica Mother Infant Cohort Study [20] were tested. Informed consent was obtained from study participants, and the study was approved by the institutional review boards at the University of the West Indies, the US National Cancer Institute and University of Miyazaki. These children were born to mothers positive for HTLV-1 and had been followed for over 10 years since birth. One case with sufficient specimen volume and duration of follow-up was selected from each of the 3 groups of children with low, medium or high provirus load. Cases A and B (low and medium provirus load) were asymptom- atic. Case $\mathrm{C}$ (the child with high provirus load) was selected based on the presence of clinical manifestations that included recurring history of lymphadenopathy, seborrheic dermatitis, and hyperreflexia since the patient was less than 1 year old (table 1). A low level of abnormal lymphocytes (2\%) was seen in case $\mathrm{C}$ at 2 years of age, but not at other ages.

Quantification of HTLV-1 Provirus in PBMCs

The chromosomal DNA was isolated from PBMCs by sodium dodecyl sulfate-protease K digestion, followed by phenol-chloroform extraction and ethanol precipitation [21]. PVLs were measured by real-time PCR using LightCycler DX 400 (Roche Diagnostics, Mannheim, Germany). The primers and the probe for HTLV-1 provirus were as follows: forward primer 5'-AACCAATTCATTCAAACATCTGACC-3', positions 3735-3759; reverse primer 5'-GCTTTCACAGGAGCCAATGG-3', positions 3877-3858, and FAM-labeled probe 5'-FAM-TGTTCCTATCTTACTCCACCACAGTCACCGA-TAMRA-3', positions 37673797. The nucleotide position number of HTLV-1 provirus was according to Seiki et al. (accession No. J02029) [22]. RNase P control reagent (Applied Biosystems, Foster City, Calif., USA) was used for the primers and the probe for human RNase P DNA as internal control. PVL was shown by the copy number of HTLV-1 provirus in 100,000 PBMCs.

\section{Analysis of the Pattern of HTLV-1 Proviral Integration by Inverse Long PCR}

A detailed description of the inverse long (IL)-PCR procedure has been provided elsewhere [6]. In brief, the genomic DNA was digested with EcoRI, self-ligated by T4 ligase, and then digested with MluI. Long PCR amplification of the resultant DNA was performed using the rTth DNA polymerase (Applied Biosystems). The primers used in this analysis were primer 1 in the U5 region of the long terminal repeat (LTR) 5'-TGCCTGACCCTGCTTGCTCAACTCTACGTCTTTG-3' (positions 8856-8889), and primer 2 in the U3 region of the LTR 5'-AGTCTGGGCCCTGACCTTTTCAGACTTCTGTTTC-3' (positions 123-90). The PCR products were electrophoresed on a $1.2 \%$ agarose gel, and visualized by ethidium bromide staining. All assays were performed in triplicates.

\section{Clone-Specific PCR for the Major Clones in Case C at Age 16 Years}

When PBMCs of case C were analyzed by IL-PCR, 2 major bands were shown, at ages of 13 and 16 years (clone $S 0.75 \mathrm{~kb}$ and clone $\mathrm{L} 4 \mathrm{~kb}$ ). The proviral integration sites of these clones were identified as follows. DNAs of these 2 bands in case $\mathrm{C}$ at 16 years of age were isolated from the gel and ligated with the pCR-XLTOPO vector using TOPO cloning reaction kit (Invitrogen, Carlsbad, Calif., USA). The DNA sequences of the cloned PCR products were analyzed using the ABI Prism Big Dye Terminator v1.1 Cycle Sequencing kit and an ABI Prism 310 genetic analyzer (Applied Biosystems). Based on the DNA sequence of the flanking region of the provirus derived from clones $\mathrm{S}$ and $\mathrm{L}$, integration site-specific primers were designed. Accordingly, DNAs isolated from PBMCs of case $C$ at 16 years of age were subjected to quantitative real-time PCR for clones S and L. Forward primer 5'CCAAGTACCGGCGACTCC-3' (positions 8976-8993) and probe FAM-CTCGGAGCCAGCGACAGCCTATCCT-TAMRA (positions 8999-9023) located in the U5 region of the LTR were 
used. The reverse primers for specific clones were as follows: primer for clone S: 5'-CAACTTTGTTCTTTCAGACAGTGTG3'; primer for clone L: 5'-CTGTTTCTCCCTCTTGAACTCTCC$3^{\prime}$. The copy number of the plasmid containing the DNA sequences of the cloned PCR products was calculated based on the size and weight of the plasmid DNA measured by spectrophotometry and used as a standard calibration curve.

Amplification of the Rearranged T Cell Receptor- $\gamma$ Gene of the PBMCs in Case C at Age 16 Years

The rearrangement of the T cell receptor- $\gamma$ (TCR $\gamma$ ) gene was detected by PCR described by Benhattar et al. [23], using primers TVG 5'-AGGGTTGTGTTGGAATCAGG-3' and TJG 5'-CGTCGACAACAAGTGTTGTTCCAC-3'. Amplified products were electrophoresed on a $10 \%$ nondenaturing polyacrylamide gel, and visualized by ethidium bromide staining. Clonally rearranged TCR $\gamma$ gene was identified based on the sharp and dominant band on the gel. Additionally, the PCR products were subcloned and sequenced using TOPO XL PCR Kit (Invitrogen), Big Dye Terminator v1.1 Cycle Sequencing Kit (Applied Biosystems), and ABI Prism 310 DNA Sequencer (Applied Biosystems).

\section{Results}

Sequential Change of HTLV-1 Proviral Loads and Clonalities of Infected Cells

The PVLs in cases A and B remained stable during the entire follow-up period (case A: 260, 850 and 573 copies in 100,000 PBMCs at ages of $1,4.5$, and 12.8 years, respectively; case B: $1,867,2,199$ and 2,187 copies in 100,000 PBMCs at ages 3, 5.6 and 13.1 years, respectively; fig. 1). When the PBMCs were analyzed by IL-PCR, case A demonstrated many bands of various sizes in the sample drawn at age 1 year. These bands represented HTLV-1infected cells with different proviral integration sites. They appeared in a stochastic manner in the triplicate experiments shown on the gel (minor bands; fig. 2a). This stochasticity was also observed for this case's samples obtained at ages of 4.5 and 12.8 years. No band was consistently detected at different time points. In case B, who had a slightly higher PVL than case A, several bands were detected in all triplicate experiments of IL-PCR (major bands; arrows, fig. $2 \mathrm{~b}$ ), in addition to the minor bands. These major bands were also detectable in the samples obtained at ages of 5.6 and 13.1 years.

Case $\mathrm{C}$ had a history of recurring lymphadenopathy, seborrheic dermatitis, and hyperreflexia since early childhood (table 1). The initial PVL in case $C$ was the highest among the 3 children, even at ages 1.9 and 5 years (2,819 and 3,005 copies per 100,000 PBMCs, respectively). The PVL in case C markedly increased to 13,358 copies in 100,000 PBMCs at age 13 years and remained

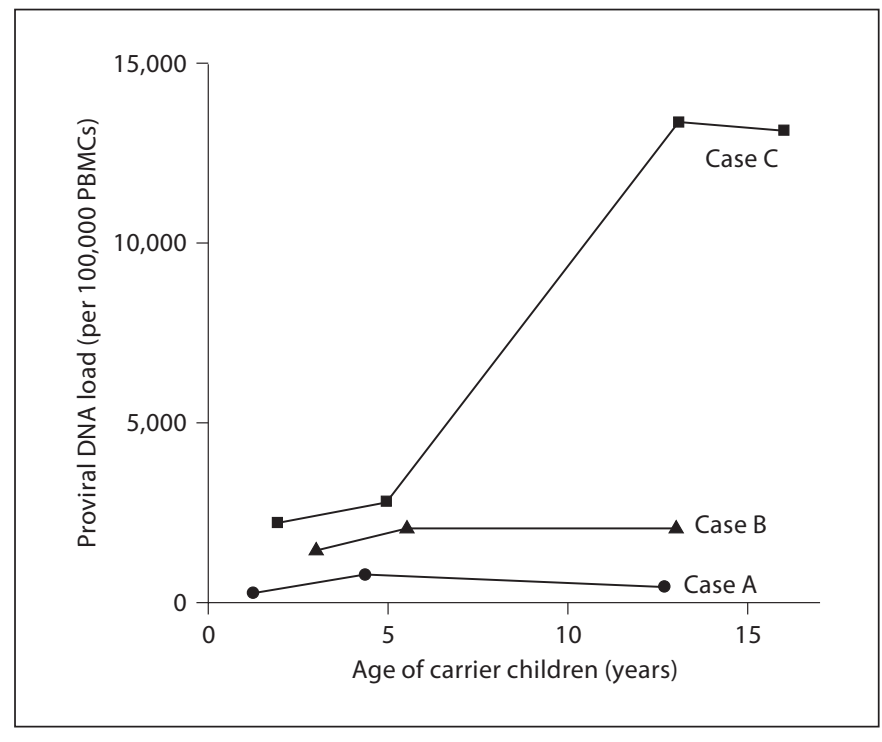

Fig. 1. Sequential change of the HTLV-1 proviral loads in the genomic DNA derived from 100,000 PBMCs of 3 carrier children.

high (13,185 copies per 100,000 PBMCs) at age 16 years (fig. 1).

When PBMCs of case C were analyzed by IL-PCR, 2 distinct bands were detected in samples drawn at ages 13 and 16 years (clone $S 0.75 \mathrm{~kb}$ and clone L $4 \mathrm{~kb}$; fig. 2c). Many additional major bands, albeit weaker in band strength, were detectable in the triplicate experiments in same samples.

\section{Clone-Specific PCR and Quantification of the PVL for Clones $S$ and $L$ from Case $C$}

The integration sites of HTLV-1 provirus for PCR products of clones $S$ and $L$ were isolated from the gel, subcloned and excised for the identification of proviral integration sites. Clones $\mathrm{S}$ and $\mathrm{L}$ were identified at $8 \mathrm{q} 22.1$ and $15 q 21.2$, respectively. HTLV-1 provirus of clone S was integrated into the transcriptional unit of the gene for phosphatidylserine synthase 1 (PTDSS1) located on chromosome 8 in the opposite direction of the cellular gene (data not shown). Integration-site-specific real-time PCR was performed using a combination of primers specific for the $3^{\prime}$-LTR of provirus and its flanking regions based on their DNA sequences. DNA sequences of clones $\mathrm{S}$ and $\mathrm{L}$ were not detectable in the sample collected at 1.9 years of age by the clone-specific real-time PCR we used. These clones were detected as 5 copies and 230 copies in 100,000 PBMCs, respectively, in a sample collected at 5 years of age (fig. 3). Copy numbers of clones $\mathrm{S}$ and $\mathrm{L}$ increased at 


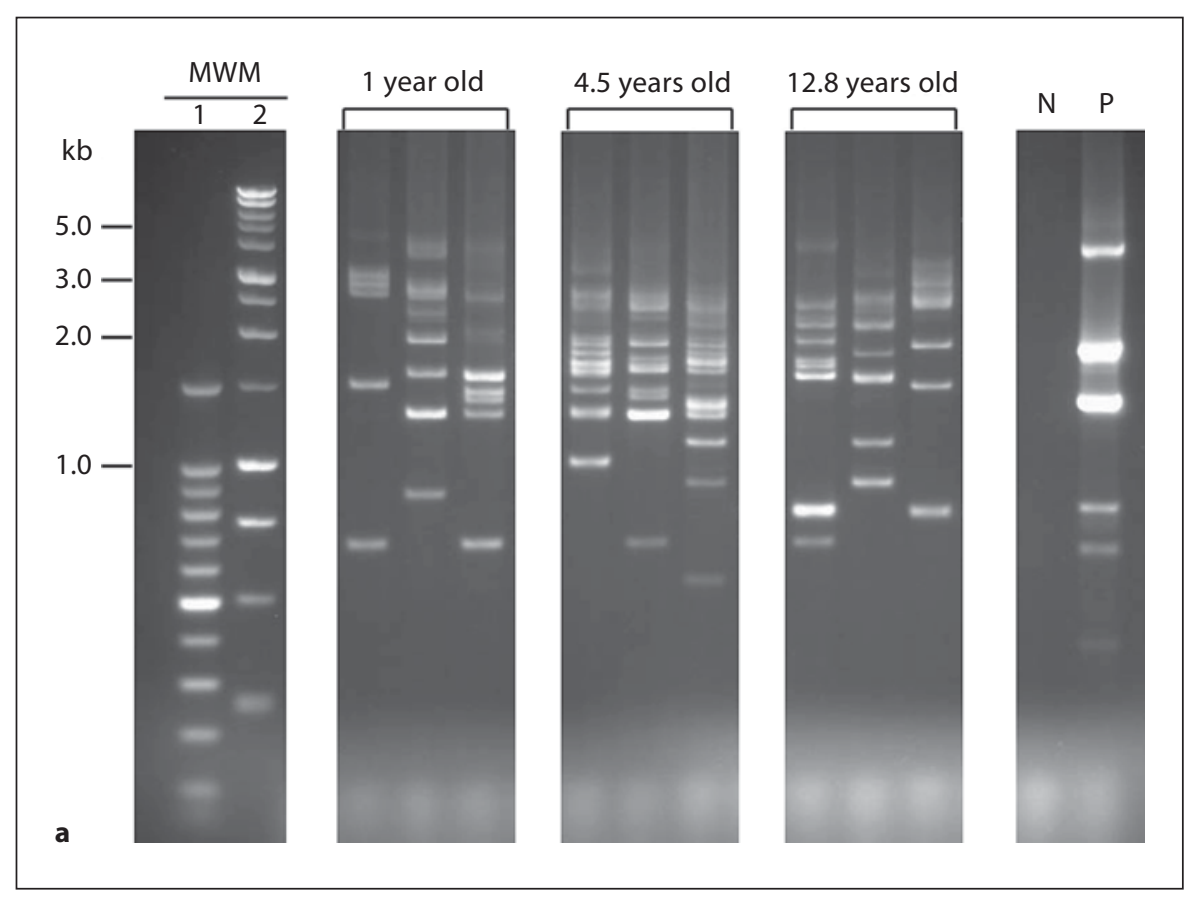

Fig. 2. Inverse long PCR analysis of HTLV1-infected cells from carrier children. Triplicate analysis of PBMCs was performed in each experiment. MWM 1 = Low-molecular-weight DNA marker; MWM 2 = high-molecular-weight DNA marker; $\mathrm{N}=$ PBMCs from HTLV-1-negative subject as negative control; $\mathrm{P}=\mathrm{HTLV}$ 1-infected cell line, HUT102, as positive control. a Analysis of case A at ages 1, 4.5 and 12.8 years. $\mathbf{b}$ Analysis of case $B$ at ages 3, 5.6 and 13.1 years. Arrows indicate the bands detected in all triplicate analyses.

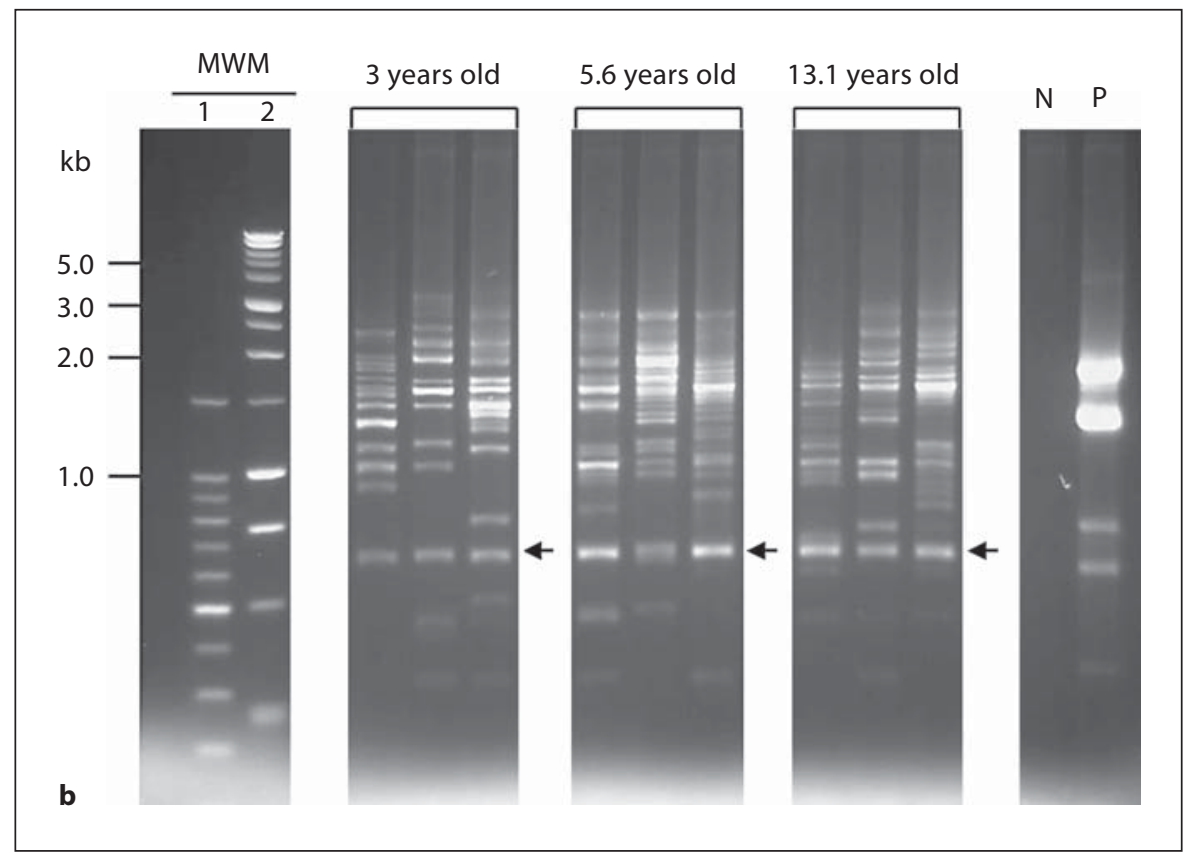

ages 13 (426 and 554 copies, respectively) and 16 years (768 and 594 copies, respectively).

\section{Rearrangement of the TCR $\gamma$ Gene of PBMCs in}

Case C

Whether or not the rearrangement of the TCR $\gamma$ gene was detectable by PCR was tested in the sample of case C at age 16 years. Detection of a weak but sharp band (arrow in fig. 4) suggested the clonal expansion of the cells with the rearranged TCR $\gamma$ gene. To confirm the clonal expansion of certain clones of T cells, PCR products of the TCR $\gamma$ gene were subcloned and sequenced. The frequency of PCR products derived from the clones of T cells with a unique (different) TCR $\gamma$ gene in the sample of case $\mathrm{C}$ at 
Fig. 2. c Analysis of case $C$ at ages 1.9, 5, 13 and 16 years. Arrows indicate 2 distinct bands (clone $\mathrm{S}$ and $\mathrm{L}$ ) detected in all triplicate analyses. Arrowheads indicate the week but consistently detected bands in all triplicate analyses.

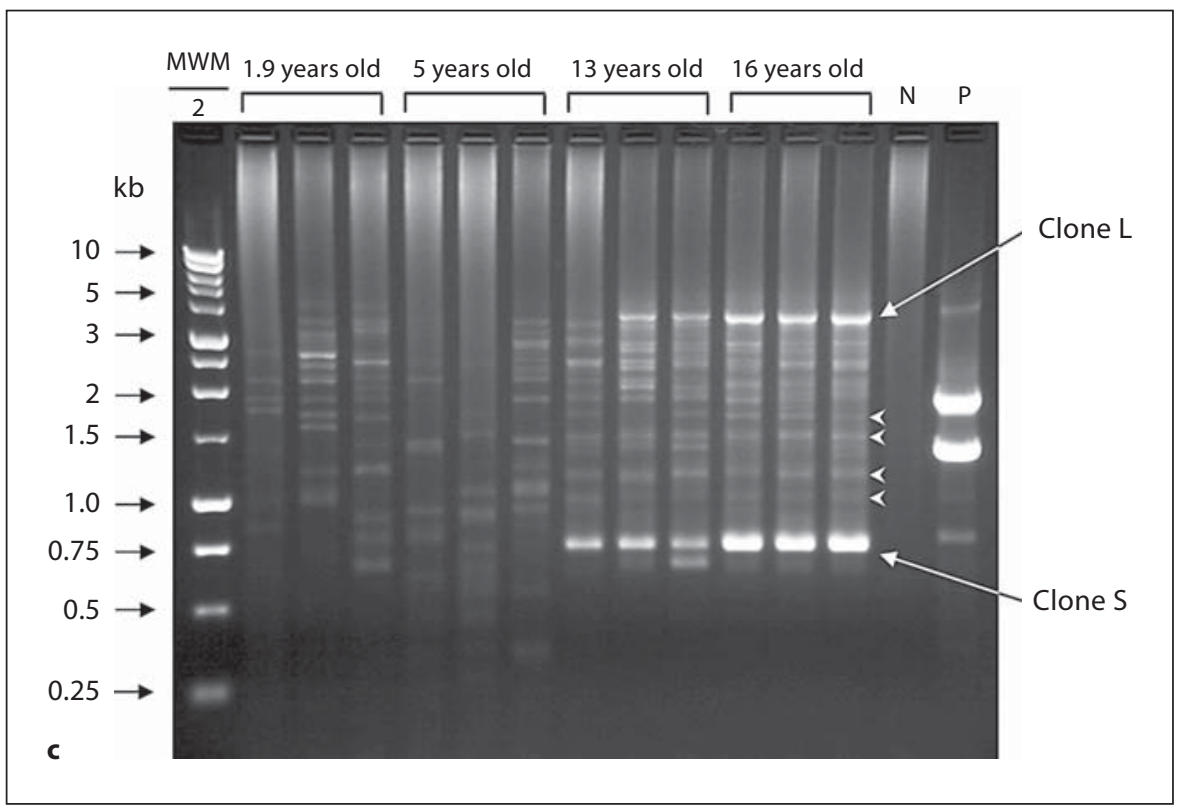

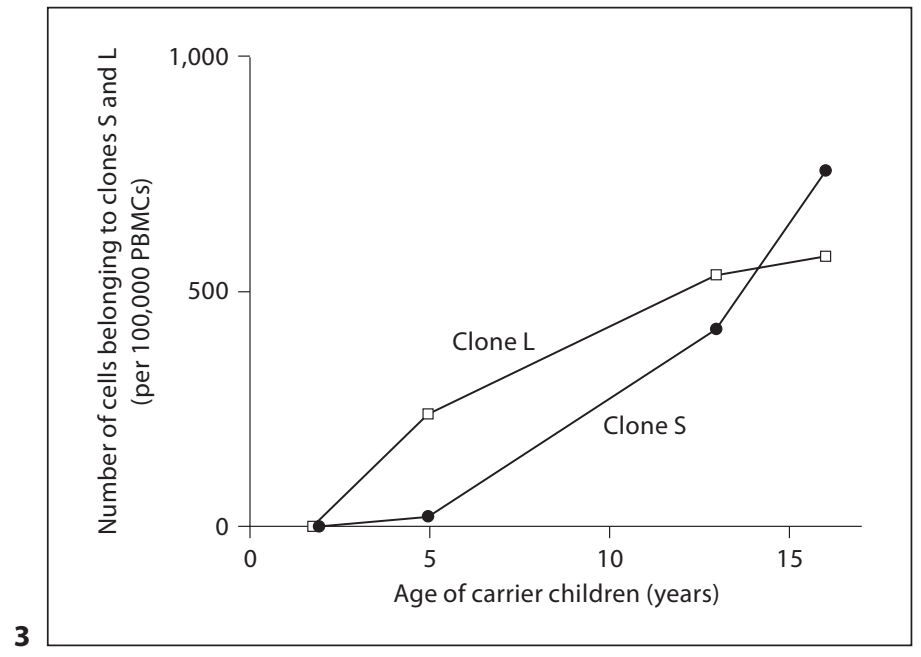

Fig. 3. Sequential change of the copy numbers of clones $\mathrm{S}$ and $\mathrm{L}$ in case $\mathrm{C}$ in 100,000 PBMCs at ages 1.9, 5, 13 and 16 years. Clonespecific quantitative real-time PCR was performed.

Fig. 4. Polymerase chain reaction analysis of the rearrangements of TCR $\gamma$ gene in case $\mathrm{C}$ at age 16 years. $\mathrm{N}=\mathrm{PBMC}$ from a healthy volunteer not infected with HTLV-1 and who is not involved in this cohort, as a negative control; HC = PBMCs from an HTLV-1 carrier, who is not involved in this cohort, as an HTLV-1-positive

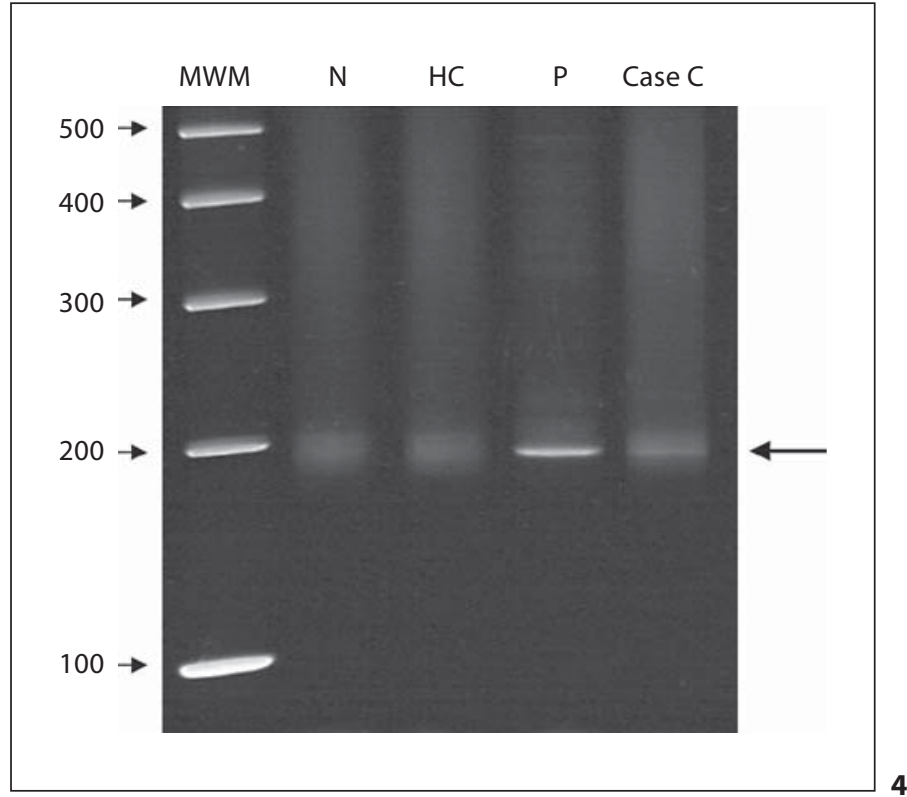

control; $\mathrm{P}=$ a patient with adult $\mathrm{T}$ cell leukemia, who is not involved in this cohort, showing a sharp and dominant band, as positive control; case $\mathrm{C}=\mathrm{PBMC}$ from case $\mathrm{C}$ at age 16 years old, who showed a weak, but evident band in a smear background (arrow). age 16 years was assessed in the resulting 128 subclones. Among 128 subclones, 5 major clones (fig. 5, closed symbols and double circles) with the same lengths and DNA sequences were repeatedly detectable in the background of minor clones (fig. 5, open circles). Each minor clone was detectable only once and exhibited different DNA sequences (fig. 5). These data confirmed the oligoclonal expansion of $\mathrm{T}$ cells in the PBMCs of case $\mathrm{C}$ at age 16 years. 
Fig. 5. Distribution of 128 subclones of the polymerase chain reaction (PCR) products of TCR $\gamma$ gene in case $C$ at age 16 years based on their variation in lengths. Each open circle indicates a unique PCR product, showing the diversity in the length and the DNA sequence. The 5 groups of PCR products indicated by the closed square, triangle, circle, diamond, and double circle indicate the clones detected repeatedly and showed identical DNA sequences.

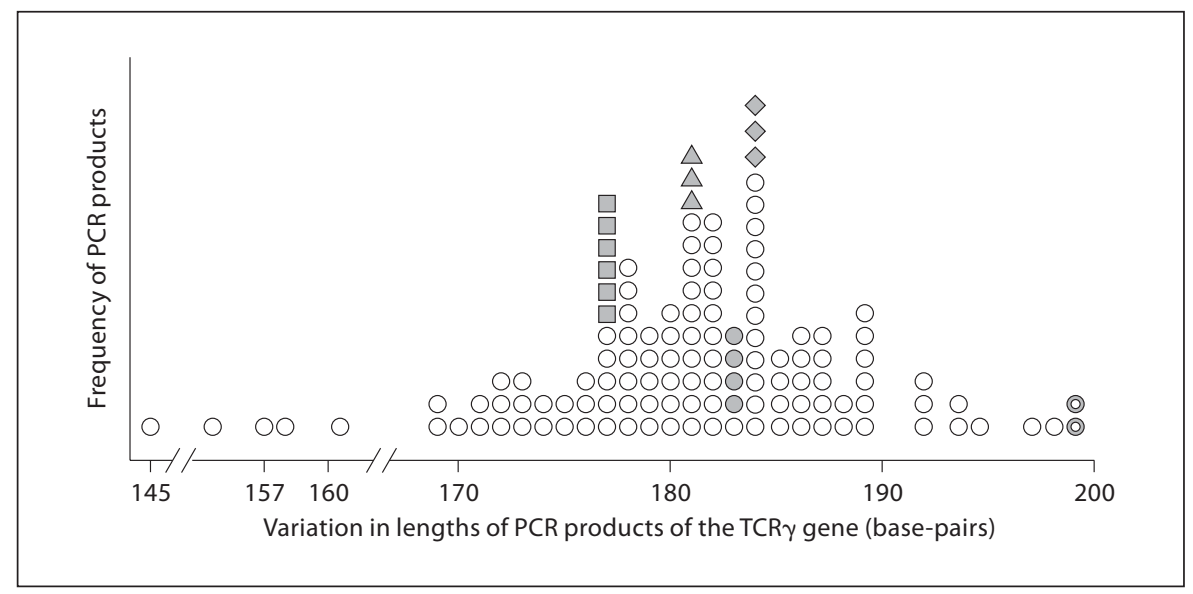

\section{Discussion}

In the present study, 3 carrier children, who were longitudinally followed for more than 10 years, were tested for PVL and clonality of HTLV-1-infected cells. This study gave us a unique opportunity to evaluate the HTLV1 infection early in the life. Two asymptomatic carrier children (cases A and B) showed stable PVL and 1 carrier child (case C), who experienced lymphadenopathy, seborrheic dermatitis and hyperreflexia, showed a prominent increase of PVL. In a previous publication, we described the pattern of changes in PVL of 28 children, including the 3 in the current analysis [11]. PVL in these vertically infected children increased up to 2 years after infection and plateaued thereafter, with an increase to a much higher PVL observed in the HTLV-1 carrier children with a diagnosis of eczema [11]. Gabet et al. [24] also reported the case of a 10-year-old girl, who was followed over a 2-year period, with infective dermatitis and infection with parasites. She had high PVLs and extensive and persistent oligoclonal expansion of infected lymphocytes, which was not influenced by clinical evolution or lamivudine treatment [24].

In the present study, when the clonality of HTLV-1infected cells was examined by IL-PCR, many bands of different sizes appeared on the gel for case A, who had relatively low PVL, representing polyclonal proliferation of HTLV-1-infected cells. Case B with relatively high PVL showed several major clones that were consistently detectable in the PBMC samples obtained at ages of 3, 5.6 and 13.1 years. The latter pattern was similar to that observed in the Japanese adult long-term carriers in the Miyazaki Cohort Study, who presumably were infected during the perinatal period [25]. These data are consistent with the hypothesis that clonal expansion may occur concurrently with increase in PVL.

Case $\mathrm{C}$ had a history of lymphadenopathy, seborrheic dermatitis and hyperreflexia. These symptoms and signs are not uncommon in the HTLV-1 carrier children in Jamaica [14]. Case $C$ showed a very high PVL and 2 distinct clones ( $\mathrm{S}$ and L) of HTLV-1-infected cells at age 13 years. The appearance of these clones coincided with a sharp increase in PVL between the ages of 5 and 13 years. DNA sequences of clones $\mathrm{S}$ and $\mathrm{L}$ were detectable by real-time PCR in case C's sample as early as 5 years of age and expanded continuously to 426 and 554 copies in 100,000 PBMCs, respectively, at 13 years of age. However, these 2 clones only accounted for less than $10 \%$ of the total PVL of case C (13,358 copies in 100,000 PBMCs). Many additional major bands were observed on the gel of the sample at the same age. Therefore, the marked increase of PVL in case $\mathrm{C}$ was considered to be due to the sum of these clones, although clone $\mathrm{S}$ and clone $\mathrm{L}$ were very evident.

It has been reported that HTLV-1 provirus is randomly integrated into the human genome. Nevertheless, proviral DNA sequences found in the ATL cells have been reported to be preferentially integrated into transcriptional units [26, 27]. It was thought that parts of corresponding genes are dysregulated, leading to proliferation of HTLV-1-infected cells. Expansion of clone S may be associated with the interaction between HTLV-1 provirus and host gene PTDSS1. However, proviral DNA of clone $\mathrm{L}$ was not integrated into the transcriptional unit. These findings suggest that integration of proviral DNA into transcriptional units is not essential for the occurrence of clonal expansion.

The high PVL and detection of 2 distinct clones of HTLV-1-infected cells in case $\mathrm{C}$ were also evident at age 
16 years, 3 years later. The analysis of the TCR $\gamma$ gene rearrangement, which does not depend on HTLV-1 proviral integration, also detected an oligoclonal expansion of $5 \mathrm{~T}$ cell clones, which were repeatedly detected by PCR in the background of many $\mathrm{T}$ cells without clonality. The occurrence of ATL in patients with a history of infective dermatitis was reported [15]. The shortened period of latency was observed in ATL patients with chronic infection, such as strongyloidiasis [28]. Fortunately, case C did not show any signs of HTLV-1-associated disease, especially ATL, at age 16 years. Our data suggest that detection of clonal expansion of HTLV-1-infected cells does not always indicate the onset of clinically evident ATL. However, continuous clinical monitoring is warranted in this case, for any early signs of HTLV-1-associated disease.

Active HTLV-1 infection may have resulted in lymphadenopathy and inflammatory diseases in case C. Alternatively, these inflammatory diseases in childhood may have stimulated the immune system of case $\mathrm{C}$, resulting in the expansion of certain $\mathrm{T}$ cells. If these activated $\mathrm{T}$ cells were infected with HTLV-1, DNA sequences of HTLV-1 provirus, especially the Tax-coding region, could have been transcribed at the same time. Therefore, it is possible that inflammatory antigenic stimulation, such as co-infection of other pathogens or allergic diseases in childhood, may induce the early clonal expansion of HTLV-1-infected T cells, leading to eventual develop- ment of ATL. The findings from the present study are suggestive, but warrant further study that includes larger number of cases.

Children infected with HTLV-1 during early childhood have an increased risk of developing ATL $[9,10]$. In the present study, high PVL and the clonal expansion of HTLV-1-infected cells were seen in 2 of 3 children who were infected from their mothers. The clonal expansion accompanied by high PVL was most evident in a child who had skin manifestations. Youths with high PVL should be carefully monitored for any signs and symptoms, because the concurrent presence of high PVL and skin manifestations in carrier children could represent underlying oligoclonal expansion of clones, and thus future risk for clinically overt HTLV-1-associated diseases [29].

\section{Acknowledgments}

We thank Mrs. Beverley Granston for her contribution to the study conduct. This study was supported in part by a grant-in-aid from the Japanese Ministry of Education, Science, Sports and Culture, and the Miyazaki Prefecture Collaboration of Regional Entities for the Advancement of Technological Excellence (JST). The Jamaica Mother Infant Cohort Study was supported by the Intramural Research Program of the NIH, National Cancer Institute, Division of Cancer Epidemiology and Genetics.

\section{References}

1 Uchiyama T, Yodoi J, Sagawa K, Takatsuki K, Uchino H: Adult T-cell leukemia: clinical and hematologic features of 16 cases. Blood 1977;50:481-492

2 Yoshida M, Miyoshi I, Hinuma Y: Isolation and characterization of retrovirus from cell lines of human adult T-cell leukemia and its imolication in the disease. Proc Natl Acad Sci USA 1982;79:2031-2035.

-3 Osame M, Usuku K, Izumo S, Ijichi N, Amitani $\mathrm{H}$, Igata $\mathrm{A}$, Matsumoto $\mathrm{M}$, Tara $\mathrm{M}$ : HTLV-I associated myelopathy, a new clinical entity. Lancet 1986;1:1031-1032.

4 Arisawa K, Soda M, Endo S, Kurokawa K, Katamine S, Shimokawa I, Koba T, Takahashi T, Saito H, Doi H, Shirahama S: Evaluation of adult T-cell leukemia/lymphoma incidence and its impact on non-Hodgkin lymphoma incidence in southwestern Japan. Int J Cancer 2000;85:319-324.

5 Yamaguchi K, Watanabe T: Human T lymphotropic virus type-I and adult T-cell leukemia in Japan. Int J Hematol 2002;76:240245 .

Clonal Expansion of HTLV-1-Infected Cells in Children
6 Etoh K, Tamiya S, Yamaguchi K, Okayama A, Tsubouchi H, Ideta T, Mueller N, Takatsuki K, Matsuoka M: Persistent clonal proliferation of human T-lymphotropic virus type I-infected cells in vivo. Cancer Res 1997;57: 4862-4867.

7 Etoh K, Yamaguchi K, Tokudome S, Watanabe T, Okayama A, Stuver S, Mueller N, Takatsuki K, Matsuoka M: Rapid quantification of HTLV-I provirus load: detection of monoclonal proliferation of HTLV-I-infected cells among blood donors. Int J Cancer 1999;81:856-864.

8 Okayama A, Stuver S, Iga M, Okamoto M, Mueller N, Matsuoka M, Yamaguchi K, Tachibana N, Tsubouchi H: Sequential change of virus markers in seroconverters with community-acquired infection of human T lymphotropic virus type I. J Infect Dis 2001;183:1031-1037.
9 Wilks R, Hanchard B, Morgan O, Williams E, Cranston B, Smith ML, Rodgers-Johnson P, Manns A: Patterns of HTLV-I infection among family members of patients with adult T-cell leukemia/lymphoma and HTLVI associated myelopathy/tropical spastic paraparesis. Int J Cancer 1996;65:272-273.

10 Bartholomew C, Jack N, Edwards J, Charles W, Corbin D, Cleghorn FR, Blattner WA: HTLV-I serostatus of mothers of patients with adult T-cell leukemia and HTLV-I-associated myelopathy/tropical spastic paraparesis. J Hum Virol 1998;1:302-305.

1 Maloney EM, Yamano Y, Vanveldhuisen PC, Sawada T, Kim N, Cranston B, Hanchard B, Jacobson S, Hisada M: Natural history of viral markers in children infected with human T lymphotropic virus type I in Jamaica. J Infect Dis 2006;194:552-560

12 LaGrenade L, Hanchard B, Fletcher V, Cranston B, Blattner W: Infective dermatitis of Jamaican children: a marker for HTLV-I infection. Lancet 1990;336:1345-1347. 
13 Maloney EM, Nagai M, Hisada M, Soldan SS, Goebel PB, Carrington M, Sawada T, Brennan MB, Cranston B, Hanchard B, Jacobson S: Prediagnostic human T lymphotropic virus type I provirus loads were highest in Jamaican children who developed seborrheic dermatitis and severe anemia. J Infect Dis 2004;189:41-45.

14 Maloney EM, Wiktor SZ, Palmer P, Cranston B, Pate EJ, Cohn S, Kim N, Miley W, Thomas TL, Blattner WA, Hanchard B: A cohort study of health effects of human T-cell lymphotropic virus type I infection in Jamaican children. Pediatrics 2003;112:e136e142.

-15 Hanchard B, LaGrenade L, Carberry C, Fletcher V, Williams E, Cranston B, Blattner WA, Manns A: Childhood infective dermatitis evolving into adult T-cell leukaemia after 17 years. Lancet 1991;338:1593-1594.

16 La Grenade L: HTLV-I-associated infective dermatitis: past, present, and future. J Acquir Immune Defic Syndr Hum Retrovirol 1996;13(suppl 1):S46-S49.

17 Yoshida M: Multiple viral strategies of HTLV-1 for dysregulation of cell growth control. Annu Rev Immunol 2001;19:475496.

-18 Okayama A, Stuver S, Matsuoka M, Ishizaki J, Tanaka G, Kubuki Y, Mueller N, Hsieh CC, Tachibana N, Tsubouchi H: Role of HTLV-1 proviral DNA load and clonality in the development of adult T-cell leukemia/lymphoma in asymptomatic carriers. Int J Cancer 2004;110:621-625.
19 Cavrois M, Leclercq I, Gout O, Gessain A, Wain-Hobson S, Wattel E: Persistent oligoclonal expansion of human T-cell leukemia virus type 1-infected circulating cells in patients with tropical spastic paraparesis/ HTLV-1 associated myelopathy. Oncogene 1998; 17:77-82.

20 Wiktor SZ, Pate EJ, Rosenberg PS, Barnett M, Palmer P, Medeiros D, Maloney EM, Blattner WA: Mother-to-child transmission of human T-cell lymphotropic virus type I associated with prolonged breast-feeding. J Hum Virol 1997;1:37-44.

21 Sambrook J, Russell DW: Molecular cloning: a laboratory manual, 3rd ed. New York, Cold Spring Harbor Laboratory Press, 2001, pp 6.4-11p.

22 Seiki M, Hattori S, Hirayama Y, Yoshida M: Human adult T-cell leukemia virus: complete nucleotide sequence of the provirus genome integrated in leukemia cell DNA. Proc Natl Acad Sci USA 1983;80:3618-3622.

23 Benhattar J, Delacretaz F, Martin P, Chaubert P, Costa J: Improved polymerase chain reaction detection of clonal T-cell lymphoid neoplasms. Diagn Mol Pathol 1995;4:108112.
24 Gabet AS, Kazanji M, Couppie P, Clity E, Pouliquen JF, Sainte-Marie D, Aznar C, Wattel E: Adult T-cell leukaemia/lymphoma-like human T-cell leukaemia virus-1 replication in infective dermatitis. Br J Haematol 2003; 123:406-412.

-25 Tanaka G, Okayama A, Watanabe T, Aizawa S, Stuver S, Mueller N, Hsieh CC, Tsubouchi $\mathrm{H}$ : The clonal expansion of human T lymphotropic virus type 1-infected T cells: a comparison between seroconverters and long-term carriers. J Infect Dis 2005;191: $1140-1147$.

-26 Ozawa T, Itoyama T, Sadamori N, Yamada Y, Hata T, Tomonaga M, Isobe M: Rapid isolation of viral integration site reveals frequent integration of HTLV-1 into expressed loci. J Hum Genet 2004;49:154-165.

27 Hanai S, Nitta T, Shoda M, Tanaka M, Iso N, Mizoguchi I, Yashiki S, Sonida S: Integration of human T-cell leukemia virus type 1 in genes of leukemia cells of patients with adult T-cell leukemia. Cancer Sci 2004;95:306310.

28 Plumelle Y, Gonin C, Edouard A, Bucher BJ, Thomas L, Brebion A, Panelatti G: Effect of Strongyloides stercoralis infection and eosinophilia on age at onset and prognosis of adult T-cell leukemia. Am J Clin Pathol 1997;107: 81-87.

-29 Farre L, de Oliveira Mde F, Primo J, Vandamme AM, Van Weyenbergh J, Bittencourt AL: Early sequential development of infective dermatitis, human $\mathrm{T}$ cell lymphotropic virus type 1-associated myelopathy, and adult $\mathrm{T}$ cell leukemia/lymphoma. Clin Infect Dis 2008;46:440-442. 